\title{
GÊNERO, CORPO E COLONIALIDADE: DESLOCAMENTOS EPISTEMOLÓGICOS E FEMINISMOS A MARGEM DO SUL GLOBAL
}

\author{
Flávia Pereira Machado \\ Instituto Federal de Goiás, Brasil \\ E-mail: flavia.ifg.machado@gmail.com \\ ORCID: https://orcid.org/0000-0003-4676-5351
}

Data de recebimento: $21 / 07 / 2020$

Data de aprovação: 29/09/2020

DOI: https://doi.org/10.30612/frh.v22i40.13262

\begin{abstract}
Resumo: No presente artigo proponho evidenciar os elementos centrais que demarcam os feminismos latino-americanos a partir dos deslocamentos epistemológicos engendrados no Sul global em contraposição às perspectivas eurocentradas e, em especial, ao feminismo hegemônico/ocidental. Para tanto, recorro a uma revisão da literatura em torno da crítica à colonialidade do poder, colonialidade de gênero e colonialidade discursiva dos feminismos hegemônicos no sul a partir dos debates engendrados pelas críticas feministas decoloniais, no sentido da construção de um conhecimento situado para a produção de epistemologias feministas latino-americanas a partir das margens (BIDASECA et al, 2011). O objetivo é situar teoricamente o conceito de feminismos decoloniais como categoria-ferramenta de análise.
\end{abstract}

Palavras-chave: gênero, corpo, colonialidade, feminismos decoloniais.

\section{GÉNERO, CUERPO Y COLONIALIDAD: CAMBIOS EPISTEMOLÓGICOS Y FEMINISMOS EN LOS MÁRGENES DEL SUR GLOBAL}

Resumen: En este artículo me propongo destacar los elementos centrales que delimitan los feminismos latinoamericanos de los cambios epistemológicos engendrados en el Sur global en contraposición a las perspectivas eurocéntricas $y$, en particular, el feminismo hegemónico/occidental. Para ello, recurro a una revisión de la literatura en torno a la crítica de la colonialidad del poder, la colonialidad del género y la colonialidad discursiva de los feminismos hegemónicos del Sur a partir de los debates engendrados por la crítica feminista descolonial, en el sentido de construir un conocimiento situado para la producción de epistemologías feministas latinoamericanas desde los márgenes (BIDASECA et al, 2011). El objetivo es situar teóricamente el concepto de los feminismos descoloniales como una categoria- herramienta de análisis.

Palabras clave: género, cuerpo, colonialidad, feminismos decoloniales.

\section{GENDER, BODY AND COLONIALITY: EPISTEMOLOGICAL SHIFTS AND FEMINISMS ON THE MARGINS OF THE GLOBAL SOUTH}

\begin{abstract}
In this article I propose to highlight the central elements that demarcate Latin American feminisms from the epistemological shifts engendered in the global South as opposed to Eurocentred perspectives and, in particular, hegemonic/western feminism. To this end, I
\end{abstract}


resort to a literature review around the critique of the coloniality of power, gender coloniality and discursive coloniality of hegemonic feminisms in the South from the debates engendered by decolonial feminist critiques, towards the construction of a knowledge situated for the production of Latin American feminist epistemologies from the margins (BIDASECA et al, 2011). The aim is to situate theoretically the concept of decolonial feminisms as a tool category for analysis.

Keywords: Gender, Body, Coloniality, Decolonial Feminisms.

\title{
Prólogo: quando as "outras" dos feminismos hegemônicos se erguem
}

\begin{abstract}
Nossos corpos tem a forma de mulheres, de lésbicas, de trans, de gays, de dissidentxs do patriarcado e da heteronorma. São corpos que guardam a memória de nossas ancestrais indígenas, negras, mestiças, migrantes, desenraizados de territórios brutalmente colonizados. São corpos que descobriram no andar consciente de si mesmos, espaços para o desejo e para a liberdade.

Nos muitos nascimentos que temos e que acompanhamos, parteiras $e$ parturientes que somos, aprendemos que nossos olhares provêm de distintas experiências. Nos conhecemos com diferentes idades, variadas memórias e histórias, que se entrelaçam em um tecido comunitário, que borda a realidade em movimento e a partir dos movimentos populares. Um tecido com fios que desenham e transbordam o tempo que vivemos, colorindo com tinturas naturais, com infinitos matizes, tomando as tonalidades da terra, dos rios, dos bosques, da natureza que somos, e de nossas paisagens subjetivas e subversivas.
\end{abstract}

(Cláudia Korol, 2016; tradução minha)

Em um espaço de disputas políticas, discursivas e narrativas corpos se erguem na busca não apenas por visibilidade, mas dizibilidade. São corpos-território de mulheres indígenas, camponesas, afrodescendentes, diaspóricas, migrantes, lésbicas, trabalhadoras urbanas e rurais, sem terra, trabalhadoras sexuais, trans, entre outras, que foram marginalizadas, excluídas e/ou silenciadas nos movimentos feministas hegemônicos e em suas produções teóricas ao definirem a mulher enquanto uma categoria universal, estabelecida a partir da evocação de uma identidade única para o movimento (DESCARRIÈS, 2000). A emergência dessas novas protagonistas nos espaços políticos e públicos colocam em xeque tal concepção da mulher erigida pelas feministas da segunda onda, no bojo da corrente identificada por Francine Descarriès (2000) como feminismo igualitário. Diante da complexificação dos movimentos feministas e a pluralização das sujeitas dos feminismos, proponho analisar neste artigo os elementos que corroboram para a construção de um conhecimento situado na produção de epistemologias feministas latinoamericanas a partir das críticas ao feminismo hegemônico erigido nas margens do Sul. Por 
Gênero, corpo e colonialidade: deslocamentos epistemológicos e feminismos a margem do sul global Flávia Pereira Machado

meio da revisão da literatura em torno das discussões acerca da colonialidade, da colonialidade de gênero e das colonialidades discursivas dos feminismos hegemônicos no Sul global objetivo evidenciar a constituição de feminismos outros.

Mobilizadas em frentes, coalizações, marchas, movimentos, partidos, associações, mulheres do Sul global se organizam a partir de suas vivências, experiências e ancestralidades. Subvertem não apenas a lógica de exclusão política e social, mas insurgem em novas estratégias de articulação e "resistências rebeldes e criativas" (KOROL, 2016, p. 11-12; tradução minha) ${ }^{1}$. Ações/reações mediante um cenário marcado pela grande exploração do trabalho, pelo crescimento do desemprego, subemprego e informalidade, além da ação dos capitais transnacionais na expropriação dos territórios e bens naturais, na implementação de políticas de privatização para a educação, saúde, habitação e empresas estatais, além dos golpes políticos. É neste processo de colonialidade do poder e de recolonização efetiva que se situam os feminismos latino-americanos.

Para Valería Fernández Hasan (2011, p. 379; tradução minha) as preocupações políticas e temáticas dos feminismos latino-americanos neste início do século XXI "recolocam a tensão entre o global e o local, o central e o periférico, o subordinado, o hegemônico, o contra hegemônico". Os debates evocam, assim, não apenas a dimensão das opressões por um viés interseccional, mas ainda incidem sobre a crítica epistemológica da colonialidade do poder e do saber, especificamente a colonialidade discursiva dos feminismos hegemônicos no Sul que recolocam a relação de ambivalência entre colonizador/colonizada, assim como estabelecem políticas de representação das mulheres subalternas externas às suas vozes (BIDASECA et al, 2011).

Para tanto, localizo o debate a partir da colonialidade do poder e do pensamento abissal $^{2}$ no sentido de evidenciar como a subalternidade tem sido construída em termos políticos

\footnotetext{
${ }^{1}$ Cito como exemplo desse emergir de mulheres: o feminismo comunitário de AbyaAyla na Bolívia, Guatemala e outros países da América Latina; os feminismos populares; no Brasil a Marcha das Margaridas, a Marcha das Mulheres Indígenas, o movimento "\#elenao"; na Argentina o movimento "Ni una a menos", o movimento pelo Aborto Legal, as madres e abuelas da Plaza del Mayo; o transfeminismo; entre outros.

${ }^{2} \mathrm{O}$ pensamento abissal é definido pelo tracejamento de linhas abissais. Estas são compreendidas por Santos (2010, p. 32) como distinções invisíveis que "são estabelecidas através de linhas radicais que dividem a realidade social em dois universos distintos: o universo 'deste lado da linha' e o universo 'do outro lado da linha'. A divisão é tal que 'o outro lado da linha' desaparece enquanto realidade, torna-se inexistente, e é mesmo produzido como inexistente". Desta forma, o que é produzido como inexistente é excluído de maneira radical, já que não se coloca como passível de ser incluído, nem há possibilidade de uma coexistência, o que caracteriza o pensamento abissal. Santos afirma que a primeira linha global moderna se deu provavelmente com o Tratado de Tordesilhas em 1494, porém considera que as verdadeiras linhas abissais emergiram em meados do século XVI a partir do debate jurídico e político entre os estados europeus acerca do Novo Mundo, onde determinou-se o colonial, visto como o grau
} 
e epistemológicos, compreendendo que o feminismo hegemônico se constitui a partir deste construto. Em um segundo momento, identifico o debate acerca da reconceitualização do gênero a partir da perspectiva da colonialidade do gênero em que se estabelece a necessidade de evocar a interseccionalidade entre gênero, raça, sexualidade e colonialidade para situar as sujeitas dos feminismos latino-americanos, o que remete à sua superação a partir dos feminismos decoloniais.

\section{Colonialidade do poder e o pensamento abissal: reflexões a partir das epistemologias do Sul global}

O sonho é o instante em que nós estamos conversando e ouvindo os nossos motivos, os nossos sábios, que não transitam aqui nesta realidade. É um instante de conhecimento que não coexiste com este tempo aqui. (Ailton Krenak, 1989)

Refletir sobre os feminismos latino-americanos e decoloniais nos remete a construção da América "denegada", constituída na formação histórico-cultural brasileira "ladinoamefricana" conforme teorizado por Lélia Gonzalez (1988). A denegação, termo freudiano apropriado pela autora, é um "processo pelo qual o indivíduo, embora formulando um de seus desejos, pensamentos ou sentimentos, até aí recalcado, continua a defender-se dele, negando que lhe pertença” (LAPLANCE; PONTALIS, 1970 apud GONZALEZ, 1988, p. 69). Desta maneira Gonzalez ao utilizar tal termo para referir-se à América, compreende que esta é concebida a partir da negação do pertencimento às suas matrizes indígenas e africanas, principalmente no que tange ao Brasil, introjetando-se uma linha de continuidade histórica em relação à Europa e cultura ocidental, exógena à nossa formação histórico-cultural, impulsionada pelo processo de colonização, pelas políticas de branqueamento racial e genocidas.

Assim, as novas identidades raciais erigidas por meio e pelo Outro europeu, constituída a partir de uma origem colonial, patriarcal, racista, etnocida e desigual, provocaram a homogeneização dos corpos, sexos, gêneros e culturas a partir de uma matriz colonial de poder, a colonialidade, que segundo Walter Mignolo (2017), é o lado mais escuro da modernidade. Para Mignolo (2017, p. 2) a modernidade é "uma narrativa complexa, cujo ponto de origem foi

zero a partir do qual são construídas as modernas concepções de conhecimento e direito. Tais concepções estabelecem a coexistência entre a sociedade civil, hegemônica europeia, e o estado da natureza, o Outro colonial passível de dominação e objeto da violência e negação da natureza humana. 
a Europa, uma narrativa que constrói a civilização ocidental ao celebrar as suas conquistas enquanto esconde, ao mesmo tempo, o seu lado mais escuro, a "colonialidade". Portanto, não há modernidade sem colonialidade.

Esta matriz colonial de poder reverbera no cenário mundial marcado, nos últimos anos, pelo acirramento dos conflitos, desigualdades, crises econômicas, aumento das violências e formas de opressão, assim como a desumanização de grande parte dos sujeitos e sujeitas que compõem o Outro do Norte global. Tais sujeitos e sujeitas são constituídos como seres abjetos, desumanizados e racializados no processo colonizador, material e discursivamente subalternizados ao projeto da colonialidade e na perspectiva eurocentrada de produção do conhecimento. Esta matriz colonial do poder assume, assim, o controle dos corpos, sexos e gêneros haja vista que a "modernidade produz feridas coloniais, patriarcais (normas e hierarquias que regulam o gênero e a sexualidade) e racistas (normas e hierarquias que regulam a etnicidade), promovem o entretenimento banal e entorpece o pensamento" (MIGNOLO, 2014, p. 7; tradução minha) ${ }^{3}$.

Esse novo padrão mundial de poder é iniciado, conforme Aníbal Quijano (2005), com a constituição da América no século XVI e do capitalismo colonial/moderno e eurocentrado que culmina na globalização atual. Um dos eixos fundamentais desse padrão de poder é a classificação social da população mundial a partir da ideia de raça, uma construção mental que expressa a experiência básica de dominação colonial e que desde então perpassa as dimensões mais importantes do poder mundial, incluindo a sua racionalidade específica, o eurocentrismo. Este eixo tem, portanto, origem e caráter colonial, porém mais duradouro e estável que o colonialismo, matriz em que se estabeleceu, e deu origem ao elemento de colonialidade no padrão de poder hoje hegemônico.

A colonialidade é um dos elementos constitutivos e específicos do padrão mundial do poder capitalista. Sustenta-se na imposição de uma classificação racial/étnica da população do mundo como pedra angular do referido de poder e opera em cada um dos planos, meios e dimensões, materiais e subjetivos, da existência social quotidiana e da escala societal. Origina-se e mundializa-se a partir da América. (QUIJANO, 2010, p. 84).

\footnotetext{
3 "La modernidade produce heridas coloniales, patriarcales (normas y jerarquias, que regulen el género y la sexualidade) y racistas (normas y jerarquias que regulen la etnicidad), promueve el entretenimento banal y narcotiza el pensamento" (MIGNOLO, 2014, p. 7).
} 
O novo padrão de poder mundial impõe, assim, por meio da ideia de raça a legitimação das relações de dominação que é posteriormente reafirmada pela elaboração da perspectiva eurocêntrica de conhecimento, ressignificando "as antigas ideias e práticas de relações de superioridade/inferioridade entre dominantes e dominados" (QUIJANO, 2005, p. 118), a partir da naturalização da inferioridade. Somada à raça, a questão do trabalho e gênero se colocarão, dentro do capitalismo mundial, como as três instâncias centrais para a ordenação das relações de exploração/dominação/conflito (QUIJANO, 2010).

Deste modo, a matriz colonial de poder opera através de quatro domínios interrelacionados: o controle da economia; da autoridade; do gênero e da sexualidade; e do conhecimento e da subjetividade (MIGNOLO, 2017). A base de sustentação destes domínios centra-se no fundamento racial e patriarcal do conhecimento, o que provocou a imposição de uma lógica cristã, branca, androcêntrica, heteronormativa. Estabelecendo-se não apenas uma colonialidade do poder, mas também do ser e do saber por meio da regulação das formas de vida, sociedade e economia (MIGNOLO, 2014).

[...] a geopolítica e a corpo-política (entendidas como a configuração biográfica de gênero, religião, classe, etnia e língua) da configuração do conhecimento e dos desejos epistêmicos foram ocultadas, e a ênfase foi colocada na mente em relação ao Deus e em relação à razão. Assim foi configurada a enunciação da epistemologia ocidental, e assim era a estrutura da enunciação que sustentava a matriz colonial. (MIGNOLO, 2017, p. 6)

Destarte, Catherine Walsh (2009), a partir da leitura de Quijano, evidencia que a partir da delimitação da ideia de raça como instrumento de classificação social e o desenvolvimento do capitalismo, instituiu-se a "colonialidade do poder" a partir do estabelecimento e fixação de uma hierarquia racializada; a "colonialidade do ser" por meio da definição de categorias binárias legitimadoras da condição de superioridade/inferioridade em relação aos europeus/ não europeus; a "colonialidade do saber" que pressupõe o eurocentrismo como perspectiva hegemônica; e uma "colonialidade cosmogônica" que nega/ anula as cosmovisões, filosofias, religiosidades, princípios e sistema de vida do Outro não-europeu.

Erigiram-se, neste sentido, uma epistemologia ocidental, universalizada e homogeneizada mundialmente, que provocou um epistemicídio das comunidades não ocidentais (cf. SANTOS, 2010; CARNEIRO, 2005; QUIJANO, 2005). Tal epistemicídio é representativo da permanência/ continuidade do pensamento moderno ocidental que opera, de acordo com Boaventura de Sousa Santos (2010) por linhas abissais. Para o autor, estas linhas 
abissais dividem o mundo humano do sub-humano e estão novamente em movimento na contemporaneidade, de um lado pelo movimento de regresso do colonial e do colonizador e de outro pelo contramovimento do cosmopolitismo subalterno ${ }^{4}$.

$\mathrm{Na}$ perspectiva de traçar possibilidades de superação da colonialidade do saber/poder/ser e do pensamento abissal é preciso que haja não apenas uma resistência política, mas também uma resistência epistemológica (SANTOS, 2010). Em detrimento ao modelo de racionalidade ocidental que constrói uma compreensão do mundo centrada no Ocidente, criando e legitimando o poder social ao reduzir o presente e expandir o futuro, por meio das ideias de totalidade e progresso (SANTOS, 2004; 2010); é preciso eleger outros saberes, não científicos e não filosóficos, assim como outras formas de organização da vida do Sul globais. Assim, em contraposição a racionalidade ocidental demanda-se a construção de novos modelos de racionalidade em que as experiências sociais que foram/são ignoradas pela razão indolente sejam evocadas como saberes e conhecimentos válidos.

Catherine Walsh (2009), a partir da discussão sobre a interculturalidade crítica, compreende que o enfrentamento da colonialidade do poder, do ser, do saber e cosmogônico, não se restringe às esferas políticas, sociais e culturais, mas também no campo epistêmico e ontológico, articulando-se com o projeto político da decolonialidade. Neste sentido, a autora afirma que o desafio incide no questionamento das estruturas sociais, políticas e epistêmicas da colonialidade, por meio de uma política epistêmica da interculturalidade e de epistemologias políticas e críticas.

Compreendo assim que os deslocamentos epistemológicos propostos pelos feminismos decoloniais se articulam em duas frentes: primeiro no enfrentamento da instância enunciativa da matriz colonial fundamentada no racismo e no patriarcado, haja vista que "as diferenças coloniais e imperiais também moldaram relações patriarcais, uma vez que as relações hierárquicas sexuais dependem muito, no mundo moderno/colonial, da classificação racial" (MIGNOLO, 2017, p. 10). Segundo, na desconstrução dos discursos coloniais e salvacionistas engendrados pelo feminismo clássico e hegemônico, desenvolvido por "um grupo concreto de

\footnotetext{
${ }^{4}$ O cosmopolitismo subalterno é definido por Santos (2010) como um novo pensamento, um pensamento pósabissal, como uma reação epistemológica frente ao pensamento abissal e ao epistemicídio. Este "manifesta-se através das iniciativas e movimentos que constituem a globalização contra hegemônica. Consiste num vasto conjunto de redes, iniciativas, organizações e movimentos que lutam contra a exclusão econômica, social, política e cultural gerada pela mais recente encarnação do capitalismo global, conhecido como globalização neoliberal" (p. 51). O ponto de partida é a diversidade do mundo que demanda a construção de uma diversidade epistemológica, portanto, o cosmopolitismo subalterno é marcado pela incompletude.
} 
mulheres, que por suas origens de classe, etnia, raça, nacionalidade e por sua situação geográfica possuem e desfrutam de uma vantagem epistêmica” (MENA, 2017, p. 95; tradução minha).

\section{Colonialidade do gênero e feminismos decoloniais: repensando conceitos, práticas e epistemologias}

Qualquer discussão sobre a construção intelectual e política dos "feminismos do terceiro mundo" deve tratar dos projetossimultâneos: a critica interna dos feminismos hegemônicos do "Ocidente", e a formulação de interesses e estratégias feministas baseadas na autonomia, geografia, história e cultura. O primeiro é um projeto de desconstrução e desmantelamento e o segundo, de construção e criação.

(Chandra T.Mohanty, 2008)

Identificadas nos interstícios das lutas contra hegemônicas e insurgentes dentro de um sistema de múltiplas opressões, as mulheres latino-americanas na contemporaneidade são localizadas a partir do processo de descentramento e pluralização dos feminismos no Brasil e na América Latina (ALVAREZ, 2004). Este processo é definido por Sônia E. Alvarez (2004) em torno de quatro características: 1) ampliação dos lugares nos quais os discursos e as práticas feministas circulam, onde consequentemente são desestabilizados ou impactam nos sentidos e significados dominantes; 2) crescente visibilidade e dinamismo de novas agentes no campo dos movimentos feministas que se apropriam e ressignificam o feminismo, fundando uma nova perspectiva em que as identidades e condições de raça, de classe, de sexualidade e de idade como constitutivas do ser mulher ou de homem; 3) proliferação de novos discursos contestatórios sobre a dominação com base no gênero e a sua vinculação com outros vetores do poder e da discriminação, o que a teoria feminista afro-americana compreende como interseccionalidade (interconexão de gênero, classe, sexualidade e raça), o que abre caminho para uma desconstrução do sujeito mulher e na reconstrução do feminismo baseado nas alianças e na solidariedade entre mulheres diferentes e desiguais; 4) reconceitualização do gênero.

Deste modo, ocorre uma reconfiguração, ressignificação e deslocamento das práticas, coalizões, conceitos e epistemologias feministas, no sentido de desvelar a colonização discursiva e a colonialidade presente no feminismo latino-americano, haja vista que este nasce no bojo das esquerdas e lutas revolucionárias dos anos 1970. Sendo assim, a produção de um ideário feminista latino-americano se desenvolveu e se fundamentou no pensamento e programa 
Gênero, corpo e colonialidade: deslocamentos epistemológicos e feminismos a margem do sul global

Flávia Pereira Machado

político do feminismo ocidental ${ }^{5}$ (MIÑOSO; CASTELLI, 2011), incorporado por mulheres brancas, heterossexuais e das elites econômicas e intelectuais ${ }^{6}$.

Para Miñoso e Castelli (2011) a preocupação em indagar os mecanismos mediante os quais o feminismo é produtor de colonialidade, emerge da experiência (e leitura das experiências) do feminismo crítico e contra hegemônico na América Latina e Caribe. Assim, o propósito é escrutinar o feminismo e constituir uma crítica direcionada aos limites da luta e dos privilégios de raça, classe e (hetero)sexualidade que operam dentro da ação política do feminismo como movimento social, assim como dentro do campo de conhecimentos abertos pelos estudos acadêmicos de gênero e sexualidade.

Deste modo, as críticas são provenientes dos posicionamentos subalternos dentro do desenvolvimento do feminismo como práxis política, como pensamento e forma de conhecer, por meio de uma “jornada epistêmica” (MIÑOSO; CASTELLI, 2011) que parte da tradição do pensamento latino-americanista desde os anos 1970 para constituir a produção de um conhecimento outro situado geopoliticamente. Nos últimos anos incorpora-se também a produção teórica e o pensamento das feministas lésbicas, imigrantes, afrodescendentes, latinas e terceiromundistas, provenientes da classe trabalhadora nos Estados Unidos; as "outras" do feminismo ocidental ${ }^{7}$. Estas corroboram no sentido de denunciar o caráter universalista, essencialista e excludente da categoria mulher ${ }^{8}$, a partir de um programa amplo de denúncia e desconstrução do saber pretensamente universalista do feminismo branco ocidental.

\footnotetext{
${ }^{5}$ Considero como feminismo ocidental e hegemônico, os movimentos políticos e teóricos desenvolvidos na Europa e Estados Unidos a partir do século XIX e narrado por meio das "ondas" feministas. Estas localizam a história, principalmente, das mulheres brancas, de classe média, educadas, eurocentradas, entre outras marcações que acabaram por excluir grande parte das mulheres do Norte e Sul global como lésbicas, negras, trabalhadoras pobres, indígenas, "mulheres de cor", entre uma diversidade de outras mulheres.

${ }^{6}$ Ana Marcela Montanaro Mena (2017) afirma que as propostas do feminismo hegemônico, incorporadas pelos projetos feministas latino-americanos, trouxeram consequências negativas já que tem permitido a instalação, reprodução e sustentação das políticas neoliberais, que provocam a exclusão e miséria das populações historicamente excluídas: indígenas, afrodescendentes, camponeses, mulheres pobres. Tal vinculação às políticas neoliberais ocorre ao conformarem organizações para o desenvolvimento de ações feministas vinculadas aos organismos de cooperação na lógica do neoliberalismo e da colonialidade, localizando tal processo entre os anos 1980 e 1990.

${ }^{7}$ Chandra Mohanty (2008) evidencia que o discurso e a prática política do feminismo ocidental não são singulares e nem homogêneos em seus objetivos, interesses ou análises, porém é possível identificar uma coerência de efeitos que resulta do suposto implícito do "Ocidente" como um referente primário no campo teórico e prático. Para a autora o feminismo ocidental não é compreendido como um conjunto monolítico, mas possuem efeitos similares nas estratégias utilizadas pelas autoras que codificam o "Outro" como não ocidental e, portanto, a si mesmas como ocidentais, de forma implícita. Neste sentido, é que se refere ao feminismo produzido na Europa e Estados Unidos, hegemonicamente, como feminismo ocidental.

${ }^{8}$ Linda Nicholson (2000) afirma que no sentido de estabelecer diferenças e semelhanças em relação ao determinismo biológico, as feministas erigiram o que ela intitulou de "fundacionalismo biológico", entendido como uma noção do relacionamento entre corpo (biologia), personalidade e comportamento. O que corroborou
} 
Gênero, corpo e colonialidade: deslocamentos epistemológicos e feminismos a margem do sul global Flávia Pereira Machado

No bojo destes debates, um dos conceitos que se colocam no centro das críticas das feministas dissidentes é o conceito de gênero. Para Judith Butler (2017) gênero é um conceito complexo e que aparece nos debates feministas de modo indeterminado. A definição das categorias de gênero acabou por naturalizar e essencializar o "feminino" e o "masculino", já que estas categorias são compreendidas pela autora como regimes de poder/discurso fundados na heterossexualidade compulsória e no falocentrismo. Ao questionar a mulher enquanto categoria universal nas teorias e discursos feministas, a autora afirma que a universalidade e unidade do sujeito do feminismo são minadas "pelas restrições do discurso representacional em que funcionam" (BUTLER, 2017, p. 23), haja vista que a especificidade do "feminino" é descontextualizada, analítica e politicamente, ao ser separada de sua constituição de classe, raça, etnia e outros eixos das relações de poder, aproximando-se de certa forma da discussão acerca da interseccionalidade.

Reverbera assim o posicionamento de intelectuais insurgentes negras e de "cor" como Lélia Gonzalez, Sueli Carneiro, bell hooks, Ângela Davis, Kimberlé Crenshaw, Glória Anzaldúa ("chicana"), entre outras, que evidenciam que a demarcação das diferenças restritas ao gênero não conseguem dimensionar a realidade das "mulheres de cor", haja vista que estas são recortadas por outras discriminações. Destarte, Kimberlé Crenshaw $(2004$, p. 8) desenvolve o conceito de interseccionalidade com o propósito de posicionar como a discriminação racial e a discriminação de gênero operam juntas, "limitando as chances de sucesso das mulheres negras". Sendo assim, as experiências das mulheres negras não podem ser enquadradas separadamente nas categorias de discriminação de gênero e discriminação racial. A interseccionalidade é vista, deste modo, como um desafio ao abordar "as diferenças na diferença". O que indica ainda a necessidade de se compreender que existem diferentes

para uma compreensão do corpo e da identidade sexual como formas únicas de demarcação das diferenças e das igualdades entre as mulheres e homens a partir de uma noção fixa do corpo que excluí a dimensão da historicidade e da mutabilidade dos sentidos/significados que este ganha em cada sociedade. O que incidiu na redução de gênero à oposição binária entre masculino e feminino e na determinação de uma "essência" ou "natureza" feminina. Determinando ainda uma "identidade feminina" única, construída socialmente, a partir da perspectiva branca, heterossexual, ocidental e de classe média, excluindo assim as mulheres negras, lésbicas, pobres, não ocidentais, enfim as mulheres do Sul global.

${ }^{9}$ María Lugones (2014b, p. 13; tradução minha) afirma que "mulheres de cor" refere-se a uma terminologia adotada "pelas mulheres subalternas, vítimas de dominações múltiplas nos Estados Unidos, esta não aponta para uma identidade que separa, mas uma coalizão orgânica entre mulheres indígenas, mestiças, mulatas, negras: cherokees, porto-riquenhas, sioux, chicanas, mexicanas. Enfim, povo, toda a trama complexa das vítimas da colonialidade do gênero. Porém participando na trama não como vítimas, mas como protagonistas de um feminismo decolonial. A coalização é uma coalização aberta, com uma intensa interação intercultural”. 
categorias de discriminação, sugerindo que nem sempre os grupos são distintos, mas podem ser sobrepostos por intersecções de raça, gênero, classe, sexualidade, geração, entre outras.

Estes questionamentos tecidos pelas mulheres de cor e do terceiro mundo ao universalismo feminista são centrados, de acordo com María Lugones (2014a), na reivindicação de que a intersecção entre raça, classe, sexualidade e gênero vai além das categorias da modernidade. Para a autora, estas categorias tratadas de modo dicotômico e hierarquizadas são centrais dentro do pensamento capitalista e moderno colonial, já que mascaram e invisibilizam as organizações sociais que existiram e existem em resistência à modernidade capitalista e estão em tensão com esta lógica. A dicotomia central da modernidade colonial, segundo a autora, é a hierarquia dicotômica entre humano e não humano, sendo imposta aos/as colonizados/as a serviço do homem ocidental, acompanhada de outras distinções hierárquicas dicotômicas, entre elas a distinção entre homens e mulheres. Essa distinção tornou-se a marca do humano e a marca do civilizado, e consequentemente, só os civilizados poderiam ser homens ou mulheres. Assim, os povos indígenas das Américas e os/as africanas/as escravizados/as eram classificados/as como espécies não humanas - como animais incontrolavelmente selvagens e sexuais.

Em crítica ao conceito eurocêntrico e heteronormativo de gênero María Lugones (2014a) incorpora a interseccionalidade das feministas "de cor" norte-americanas e o debate acerca da colonialidade do poder de Aníbal Quijano, elaborando o conceito de colonialidade de gênero a partir de três questões: o conceito de colonialidade/ modernidade europeia; eurocentrismo e a interseccionalidade raça/ gênero. Evidenciando que as demarcações de gênero, raça e colonialidade não devem ser vistas em separado, já que isso é um projeto de poder colonial, moderno e capitalista (LUGONES, 2014a; 2014b).

Lugones (2014b) apropria-se do debate de Aníbal Quijano acerca da colonialidade do poder quando este analisa o padrão de poder capitalista eurocentrado e global por meio da intersecção entre raça e gênero. Segundo a autora, Quijano evidencia que o poder está estruturado em relações de dominação, exploração e conflito entre os atores sociais que disputam quatros instâncias básicas da existência humana: sexo, trabalho, autoridade coletiva e subjetividade/intersubjetividade, seus recursos e produtos. Neste sentido, as lutas pelo controle do "acesso sexual, seus recursos e produtos" definem o âmbito do sexo/gênero e estão organizadas por eixos da colonialidade e da modernidade. Porém, a autora afirma que esta 
análise da construção moderna/colonial do gênero e seu alcance é limitada, haja vista que concebe gênero de modo restrito e hiperbiologizado.

[...] Quijano ao reduzir o gênero a organização do sexo, seus recursos e produtos parece cair em um certo pressuposto sobre quem controla o acesso e quem são constituídos como 'recursos'. Quijano parece dar por garantido que a disputa pelo controle do sexo é uma disputa entre homens, acerca do controle, por parte dos homens, sobre recursos que são pensados como femininos. Os homens tampouco parecem vistos como 'recursos' nos encontros sexuais. E não parece, tampouco, que as mulheres disputam nenhum controle sobre o acesso sexual. As diferenças se pensam nos mesmos termos com os que a sociedade lê a biologia reprodutiva. (LUGONES, 2014b, p. 23; tradução minha).

Sendo assim, a autora argumenta que a visão de Quijano pressupõe uma compreensão patriarcal e heterossexual das disputas de poder pelo controle do sexo, seus recursos e seus produtos, aceita a compreensão capitalista, eurocêntrica e global de gênero. Tal conceito é visto, a partir de uma aproximação com Oyèrónké Oyêwùmí (2014), como restrito às experiências localizadas no Ocidente, haja vista que quando outras realidades são interpretadas "com base nessas alegações ocidentais, o que encontramos são distorções, mistificações linguísticas e muitas vezes uma total falta de compreensão, devido à incomensurabilidade das categorias e instituições sociais" (OYÊWÙMÍ, 2014, p. 8).

A partir da lógica do sistema moderno colonial de gênero Lugones (2014a; 2014b) compreende que há um processo de imposição da normatividade da lógica patriarcal, branca, heterossexual e de domínio masculino, em que as mulheres brancas ocidentais não são vistas como complemento, mas como subordinadas dentro da dimensão doméstica e reprodutiva. Neste sentido, a dicotomia hierárquica como marca do humano tornou-se uma ferramenta normativa de condenação dos/das colonizados/as, impondo limites ao corpo, às posições de gênero e sexualidade, haja vista que “a 'missão civilizatória' colonial era a máscara eufemística do acesso brutal aos corpos das pessoas através de uma exploração inimaginável, violação sexual, controle da reprodução e terror sistemático" (LUGONES, 2014a, p. 938). Desta forma, a imposição do gênero como juízo normativo não visava alcançar a generização dicotomizada das colonizadas e dos colonizados, haja vista que torná-los seres humanos não era um objetivo da missão civilizatória, já que significava que ao serem transformados em homens e mulheres estariam se transformando em natureza, o que implicaria em uma redefinição da forma como 
os colonizadores são concebidos (como cultura em oposição à natureza dos corpos colonizados).

Assim, Lugones (2014a, p. 939) dimensiona que o uso do termo "colonialidade" não se restringe a nomeação do processo de classificação de povos em termos de colonialidade de poder e de gênero, "mas também o processo de redução ativa das pessoas, a desumanização que as torna aptas para a classificação, o processo de sujeitificação e a investida de tornar o/a colonizado/a menos que seres humanos".

Com o fim do processo de colonização há a continuidade da colonialidade do gênero, já que esta permanece na intersecção de gênero/raça/classe como construtos centrais do sistema de poder capitalista mundial (LUGONES, 2014a). A inexistência de mulheres colonizadas na contemporaneidade, impulsiona o enfoque nos seres que resistem à colonialidade do gênero a partir da "diferença colonial”. Deste modo, Lugones compreende que a política da resistência reside na subjetividade e intersubjetividade a partir dos agenciamentos individuais e coletivos.

Descolonizar o gênero é necessariamente uma práxis. É decretar uma crítica da opressão de gênero racializada, colonial e capitalista heterossexualizada visando uma transformação vivida do social. Como tal, a descolonização do gênero localiza quem teoriza em meio a pessoas, em uma compreensão histórica, subjetiva/intersubjetiva da relação oprimir resistir na intersecção de sistemas complexos de opressão. Em grande medida, tem que estar de acordo com as subjetividades e intersubjetividades que parcialmente constroem e são construídas "pela situação". Deve incluir "aprender" sobre povos. (LUGONES, 2014a, p. 940)

O que demandaria compreender a situação de opressão, sem sucumbir a ela. Neste sentido, é a partir da superação da colonialidade do gênero que emerge o chamado "feminismo decolonial". Para Yuderkys Espinoso Miñoso (2016) o feminismo decolonial é decorrente de correntes críticas anteriores como o feminismo negro, o feminismo de cor, o feminismo póscolonial, assim como o feminismo materialista francês e o feminismo pós-estruturalista. Avança em relação a estes no sentido de colocar em dúvida a unidade das "mulheres" de uma forma radicalmente inédita, já que parte de um ponto de inflexão em diálogo com o "giro decolonial" de reinterpretação da história a partir da chave crítica da modernidade, não somente por "seu androcentrismo e misoginia, como fez a epistemologia feminista clássica, mas por seu caráter intrinsicamente racista e eurocêntrico" (MIÑOSO, 2016, p. 144; tradução minha).

Desse modo, Miñoso defende a construção de um feminismo que se fundamente a partir dos aportes teóricos da análise da colonialidade e do racismo, não como fenômeno, mas 
sim como episteme intrínseca à modernidade e aos seus projetos libertadores. Alinhada ao pensamento de María Lugones, a autora concebe o feminismo decolonial como um movimento que reconhece, revisa e dialoga com o pensamento e as produções que estão sendo desenvolvidas por pensadoras, intelectuais, ativistas e lutadoras, feministas ou não, de descendência africana, indígena, mestiça popular, campesina, migrantes racializadas, assim como pelas acadêmicas brancas comprometidas com a subalternidade na América Latina e no mundo (MIÑOSO, 2016).

Em uma outra perspectiva, Julieta Paredes (2014) propõe a reconceitualização política do feminismo a partir dos contextos comunitários bolivianos. Para tanto, defende a superação da oposição binária entre homens e mulheres a favor da comunidade, constituída por homens e mulheres como metades imprescindíveis, complementares, não hierárquicas, recíprocas e autônomas uma da outra. O que não implica uma heteronormatividade obrigatória, visto que não se trata de um casal/par, mas de par de representação política, assim como não se refere à família, mas à comunidade.

Tal episteme estabelece uma leitura de complementariedades, reciprocidades e autonomias horizontais entre os gêneros, gerações, diferentes habilidades, saberes e sexualidades, assim como também as diferentes morfologias do corpo, das expressões e orientações sexuais, as diferentes crenças, adesões políticas, ideológicas e religiosidades. Estas complementariedades, reciprocidades e autonomias atuam dentro de uma comunidade viva que se move e projeta construindo também complementariedades não hierárquicas, reciprocidades e autonomias com outras comunidades, territórios, nações.

Julieta Paredes (2014), deste modo, defende a emergência de um feminismo comunitário ${ }^{10}$ constituído por meio das experiências históricas das comunidades indígenas de Abya Yala. Em crítica ao feminismo ocidental, Paredes afirma que este surgiu em resposta às necessidades das mulheres em sua própria sociedade, desenvolvendo assim lutas e construções teóricas que pretendem explicar sua situação de subordinação. Ao serem transpostas para o

\footnotetext{
${ }^{10}$ De acordo com Susana Sacavino (2016) o feminismo comunitário nasce na Bolívia em 2003, nos movimentos de insurreição das mulheres na luta contra o neoliberalismo e a privatização da água e a guerra do gás. A partir daí, inicia-se a "Assenblea Feminista" como espaço de reflexão do feminismo e da revolução, dando origem posteriormente ao feminismo comunitário. Agregaram a este movimento mulheres com diferentes trajetórias, ativismos, reflexões e lutas feministas de mais de vinte e um países, entre eles as pertencentes do grupo "Mujeres Creando Comunidad". Atualmente, o feminismo comunitário indígena é um movimento organizado que enriquece e amplia as lutas feministas nas terras de Abya Yala. Intitulado de Feminismo Comunitário de Abya Yala (FCAY) está presente em diversos países da América Latina e Caribe como Bolívia, Chile, Argentina, México, Colômbia e Guatemala.
} 
mundo das relações coloniais, imperialistas e transnacionais, estas teorias se converteram em hegemônicas, invisibilizando as outras realidades e os outros aportes teóricos.

O feminismo ocidental como significado não nos compreende em nossos territórios de AbyaYala e não nos compreende no sentido abrangente, isto é, não nos abarca em sua compreensão. Pressupõe que o que elas querem nós queremos ou devemos querer, isto é parcialmente aceitável para nós mulheres do sul, pois podemos estar de acordo com elas, por exemplo na luta contra a violência doméstica, mas não vamos estar de acordo com outras, por exemplo: tem que lutar contra a violência doméstica, mas também tem que lutar contra a violência estrutural que beneficia às mulheres dos países ocidentais, em relação à nós, e mais, as mulheres de classe média e burguesia, algumas autoidentificadas feministas, vivem privilégios a custa de nosso trabalho como mulheres no sul e o trabalho de homens de nossos povos também. (PAREDES; GUZMÁN, 2014, p. 15; tradução minha)

Frente a isso, Paredes entende a relevância de se partir de uma definição própria do feminismo como "a luta e a proposta política de vida de qualquer mulher em qualquer lugar do mundo, em qualquer etapa da história que se tenha rebelado ante o patriarcado que a oprime" (PAREDES, 2014, p. 76; tradução minha). A autora compreende que esta definição do feminismo permite o reconhecimento das mulheres latino-americanas, filhas e netas de ancestrais aymaras, quéchuas e guaranis (etnias indígenas), como rebeldes e antipatriarcais, assim como as localiza como "irmãs" de outras feministas no mundo, posicionando-as politicamente frente ao feminismo hegemônico ocidental.

\section{Considerações Finais e ... provisórias}

No dia que eu conseguir abrir as páginas de minh'alma e contar essas linhas de meu inconsciente coletivo - com alegrias ou dores, com prazeres ou desprazeres, com amores ou ódios, no céu ou na terra - aí sim, aí sim, vou soltar a minha voz num grito estrangulado, sufocado há cinco séculos. Quinhentos anos, de pretenso reconhecimento de nossa cidadania, não pagam o sangue derramado pelas bisavós, avós, mães e filhas indígenas deste país. Este dia certamente chegará, mesmo que eu esteja em outros planos. (Eliane Potiguara, 2004)

Percorrer as tessituras teóricas dos feminismos decoloniais nos possibilita um duplo movimento: por um lado desvelar a complexidade em que as opressões são constituídas na colonialidade, este sistema de organização, conhecimento e produção do mundo, fundamentado na classificação dos seres humanos a partir das categorias dominantes de opressão: raça, classe 
e gênero. Por outro lado, nos permite estruturar as resistências no interior da colonialidade de gênero que submete os corpos de mulheres indígenas, negras e pobres por meio de práticas e constituição de novas epistemologias que estabelecem o diálogo com as epistemologias do Sul global e as epistemologias feministas dissidentes.

Os feminismos decoloniais evidenciam a forma em que o sistema moderno colonial de gênero é correlativo ao regime heterossexual, ao racismo e ao capitalismo no marco dos processos históricos concretos da conquista e colonização da América Latina, ao incorporarem em suas análises a matriz de opressão e subordinação, os conceitos de subalternidade, colonialidade do poder e violência epistêmica (MENA, 2017).

As propostas dos feminismos decoloniais consideram, assim a necessidade de elaboração de conhecimentos situados em uma geopolítica do conhecimento a partir das margens do Sul global, dos saberes produzidos por mulheres em seus contextos tradicionais ou em novas comunidades constituídas, das memórias das lutas de mulheres indígenas e quilombolas, mulheres negras e mestiças, mulheres trabalhadoras urbanas, camponesas, "sem terra”, enfim mulheres que erguem suas vozes frente as relações patriarcais, ao modelo de conhecimento imposto e à colonialidade do gênero. Para tanto, é preciso tecer um feminismo que consiga desafiar toda a sociedade acerca das "violências contra o gênero, se inscreva em uma genealogia da memória pós-colonial, que necessita recuperar uma memória epistêmica, que não omita as contribuições do feminismo chicano (o sul do norte) mas que se situe em nosso Sul” (BISADECA, 2012, p. 42 apud MENA, 2017, p. 153).

\section{Referências}

ALVAREZ, Sonia E. A política e o político na tessitura dos movimentos feministas no Brasil e na América Latina. In: GONÇALVES, Eliane (org.). Desigualdades de gênero no Brasil: reflexões e experiências. Goiânia: Grupo Transas do Corpo, 2004, p. 15-32.

BIDASECA, Karina. LABA, Vanesa Vazquez. MIÑOSO, Yuderkis Espinosa. Prólogo. In: BIDASECA, Karina. LABA, Vanesa Vazquez (comps.). Feminismos y poscolonialidad: descolonizando el feminismo desde y en América latina. Buenos Aires: Ediciones Godot Argentina, 2011, p. 6-7.

BUTLER, Judith. Problemas de gênero: feminismo e subversão da identidade. $13^{\mathrm{a}} \mathrm{ed}$. Rio de Janeiro: Civilização Brasileira, 2017.

CARNEIRO, Aparecida Sueli. A construção do outro com não-ser como fundamento do ser. 2005. 339f. Tese (Doutorado em Educação), Faculdade de Educação, USP, São Paulo, 2005. 
CRENSHAW, Kimberlé. A interseccionalidade na discriminação de raça e gênero. In: VV.AA. Cruzamento: raça e gênero. Brasília: Unifem, 2004.

. Documento para o encontro de especialistas em aspectos da discriminação racial relativos ao gênero. Estudos Feministas, 2002, vol. 10, n. 1, pp. 171-188. Disponível em http://www.scielo.br/scielo.php?pid=S0104026X2002000100011\&script=sci abstract\&tlng=pt. Acesso em 06/07/ 2019.

DESCARRIÈS, Francine. Teorias feministas: liberação e solidariedade no plural. Textos de História, vol. 8, $\mathrm{n}^{\circ}$ 1, 2000.

GONZALEZ, Lélia. A categoria político-cultural de amefricanidade. Tempo Brasileiro. Rio de Janeiro, no 92/93 (jan/jun.), 1988, p. 69-82.

HASAN, Valería Fernández. Consideraciones sobre los feminismos en América Latina. Producción teórica y prácticascomunicacionalesenla red. In: BIDASECA, Karina. LABA, VanesaVazquez (comps.). Feminismos y poscolonialidad: descolonizando el feminismo desde y en América latina. Buenos Aires: EdicionesGodot Argentina, 2011, p. 379-391.

KOROL, Cláudia. Feminismos populares. Lasbrujas necessárias enlos tempos de cólera. In: . (comp.). Feminismos populares: pedagogías y políticas. Cidade Autônoma de Buenos Aires: El Colectivo; Editorial Chirimbote; America Libre, 2016, p. 15-26.

KRENAK, Ailton. Receber sonhos. In: COHN, Sérgio (org.). Ailton Krenak. Série Encontros. Rio de Janeiro: Azougue Editorial, 2015, pp. 80-113.

LUGONES, María. Rumo a um feminismo descolonial. Estudos Feministas, Florianópolis, vol. 22, $\mathrm{n}^{\mathrm{o}}$ 3, p. 935-952, setembro-dezembro/2014a. Disponível em https://periodicos.ufsc.br/index.php/ref/article/view/36755.

. Colonialidad y género: hacia un feminismo descolonial. In: MIGNOLO, Walter (compilador). Género y descolonialidad. $2^{\mathrm{a}}$ ed. Ciudad Autónoma de Buenos Aires: Del Signo, 2014b.

MENA, Ana Marcela Montanaro. Una mirada al feminismo decolonial en América Latina. Madrid: Dykinson, 2017.

MIGNOLO, Walter. Introducción:¿Cuáles son los temas de género y (des) colonialidade? In: MIGNOLO, Walter (comp.). Género y descolonialidad. $2^{\mathrm{a}}$ ed. Buenos Aires: Del Signo, 2014.

. Colonialidade: o lado mais escuro da modernidade. Revista Brasileira de Ciências Sociais, vol. 32, nº 94, junho/2017.

MIÑOSO, Yuderkys Espinosa. De porqué es necessário un feminismo descolonial: diferenciación, dominaciónco-constitutiva de lamodernidad ocidental y elfin de la política de identidad. Solar, año 12, vol. 12, n. 1, Lima, pp. 141-171. Disponível em http://revistasolar.org/wp-content/uploads/2017/07/9-De-por-qu\%C3\%A9-es-necesario-un-

feminismo-descolonial...Yuderkys-Espinosa-Mi\%C3\%B1oso.pdf. Acesso em 01/12/2019.

CASTELLI, Rosario. Colonialidad y dependencia em los estúdios de género y sexualidad en América Latina: el caso de Argentina, Brasil, Uruguay y Chile. In: BIDASECA, Karina. LABA, Vanesa Vazquez (comps.). Feminismos y poscolonialidad: descolonizando el feminismo desde y en América Latina. Buenos Aires: Ediciones Godot Argentina, 2011, p. 161181. 
MOHANTY, Chandra Talpade. Bajo los Ojos de Occidente: feminismo académico y discursos coloniales. In: NAVAZ, Liliana Suárez. CASTILLO, Rosalva Aída Hernández (ed.). Descolonizando el feminismo: teorías y practicas desde los márgenes. Espanha: Cátedra, 2008, p. 112-161.

NICHOLSON, Linda. Interpretando o gênero. Estudos Feministas. Florianópolis, v. 8, n. 2, p. 9, jan. 2000. Disponível em https://periodicos.ufsc.br/index/ref/article/view/1917/38460. Acesso em 23/03/2019.

OYÊWÙMÍ, Oyèrónké. Conceituando o gênero: os fundamentos eurocêntricos dos conceitos feministas e o desafio das epistemologias africanas. Tradução para uso didático de: OYĚWÙMÍ, Oyèrónké. Conceptualizing Gender: The Eurocentric Foundations of Feminist Concepts and the challenge of African Epistemologies. African Gender Scholarship: Concepts, Methodologies and Paradigms. CODESRIA Gender Series. Volume 1, Dakar, CODESRIA, 2004, p. 1-8 por Juliana Araújo Lopes.

PAREDES, Julieta. Hilando Fino: desde el feminismo comunitário. $2^{\mathrm{a}}$ ed. México: El Rebozo/ Zapateándol/ Lente Flotante/ Encortitoque'spalargo y AliFem AC, 2014.

; GUZMÁN, Adriana. EI tejido de la rebeldia: ¿qué es el feminismo comunitario? La Paz: Comunidad Mujeres Creando Comunidad, 2014.

POTIGUARA, Eliane. Metade cara, metade máscara. São Paulo: Global, 2004.

QUIJANO, Aníbal. Colonialidade do poder e classificação social. In: SANTOS, Boaventura de Sousa. MENESES, Maria Paula (orgs.). Epistemologias do Sul. São Paulo: Cortez, 2010, p. 84-130.

. Colonialidade do poder, eurocentrismo e América Latina. In: LANDER, Edgardo (org.). A colonialidade do saber: eurocentrismo e ciências sociai - perspectivas latino-americanas. Buenos Aires: Clacso, 2005, p. 117-142.

SACAVINO, Susana. Tecidos feministas de AbyaYala: feminismo comunitário, perspectiva decolonial e educação intercultural. Uni-pluri/versidad, vol. 16, n. 2, 2016. Disponível em https://aprendeenlinea.udea.edu.co/revistas/index.php/unip/article/view/328317/20785229.

Acesso em 01/12/2019.

SANTOS, Boaventura de Sousa. Para além do pensamento abissal: das linhas globais a uma ecologia dos saberes. In: Paulo: Cortez, 2010, p. 31-83. MENESES, Maria Paula (orgs.). Epistemologias do Sul. São

Para uma sociologia das ausências e uma sociologia das emergências. In: . (org.) Conhecimento prudente para uma vida decente: "um discurso sobre as ciências" revisitado. São Paulo: Cortez, 2004, p. 777-821.

WALSH, Catherine. Interculturalidade crítica e pedagogía decolonial: in-surgir, re-surgir e reviver. In: CANDAU, Vera Maria (org.) Educação Intercultural na América Latina: entre concepções, tensões e propostas. Rio de Janeiro: 7 Letras, 2009, p. 12-42. 